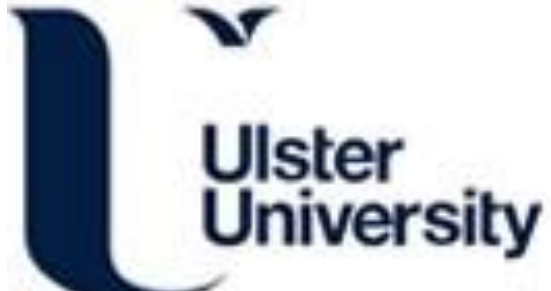

\section{Developing an open education resource to develop digital literacy skills for employability in the Life and Health Sciences}

Hack, C. (2015). Developing an open education resource to develop digital literacy skills for employability in the Life and Health Sciences. Journal of Educational Innovation, Partnership and Change, 1(1), n-n.

https://journals.gre.ac.uk/index.php/studentchangeagents/article/view/206

Link to publication record in Ulster University Research Portal

Published in:

Journal of Educational Innovation, Partnership and Change

Publication Status:

Published (in print/issue): 13/03/2015

\section{Document Version}

Publisher's PDF, also known as Version of record

\section{General rights}

Copyright for the publications made accessible via Ulster University's Research Portal is retained by the author(s) and / or other copyright owners and it is a condition of accessing these publications that users recognise and abide by the legal requirements associated with these rights.

\section{Take down policy}

The Research Portal is Ulster University's institutional repository that provides access to Ulster's research outputs. Every effort has been made to ensure that content in the Research Portal does not infringe any person's rights, or applicable UK laws. If you discover content in the Research Portal that you believe breaches copyright or violates any law, please contact pure-support@ulster.ac.uk. 


\title{
Developing an open education resource to develop digital literacy skills for employability in the Life and Health Sciences
}

\author{
Catherine Jane Hack \\ Ulster University
}

\begin{abstract}
This case study describes the development of an open educational resource (OER) designed to support students in the identification, evaluation and development of the digital literacies required for employability in the life and health sciences. The OER prompts students to recognise and evidence their existing attributes and identify areas for development; furthermore, it equips them to articulate their experiences and skills to employers. Embedded in these activities is the use of digital literacies, including information gathering, evaluation and sharing, as well as developing and promoting a professional profile. The resource was developed in partnership with students and is now being deployed and evaluated as part of an extra-curricular activity which students can use for evidence in their Higher Education Achievement Report (HEAR).
\end{abstract}

\section{Developing digital literacies}

It is widely recognised that the ability to use appropriate technologies for communication, collaboration and information management is critical for learning and professional practice. Numerous studies have demonstrated the potential of Web 2.0 services, such as blogs, social networks, social bookmarking, podcasting and immersive worlds, to facilitate collaborative and constructive learning. However, the evidence of impact on student learning is still weak (Hew and Cheung, 2013). Thus, whilst there are many studies describing the use of social networks to develop informal learning networks (for recent examples, see Vivian et al, 2014), Tambouris et al (2012) question whether the use of Web 2.0-based tools of itself promotes collaborative knowledge production. Several studies, such as Wright et al (2013) and Tambouris et al (2012), advocate caution in assuming that students possess the skills required for employability, or that they can transfer digital skills from a social to an academic or professional context. The assumption that the digital native generation is adept at using technology has been discredited (Bennett et al, 2008) and it has been realised that students require support in developing their digital competencies. In recognition of these challenges and to promote digital capability, the Higher Education Academy (HEA) funded a number of mini-projects through the Developing Digital Literacies in the Disciplines programme (2014). The aim of these projects was to support students in producing Open Educational Resources, digital materials which are subsequently made freely available to teachers and students for re-use or re-purposing in accredited or independent learning environments.

\section{Methodology for resource development and evaluation}

This project stemmed from a postgraduate module in professional practice for bioscience students. Students entering life science programmes have available to them a wide range of career options which can be broadly categorised into careers that directly use the skills and knowledge developed in their degree (e.g. laboratory- or hospital-based careers), options 


\section{Case Studies}

that use science knowledge but require further professional development (e.g. teaching, scientific journalism, regulatory affairs) and options that use the transferable skills developed through their degree programme and apply them to a different sector (e.g. finance, sales, marketing). The module aims to help students develop the requisite skills and attributes to enable them to work as bioscience professionals, including the digital skills necessary for graduate careers.

An alternative approach to the provision of digital competencies is to develop extracurricular activities that allow students to identify and develop those literacies that are important to their own personal development. The Ulster EDGE (Engagement Development Graduate Employability) Award was designed to enhance the employability of Ulster graduates by providing official recognition and evidence of activities outside their programme of study (EDGE Award, 2012). To achieve the award, students complete four activities of approximately thirty hours' duration; an activity was developed using selected content from the professional practice module as a framework from which students could develop their own digital development strategy (EDGE Award, 2013).

The aim of this project was to work with students to re-purpose the digital learning activities from the professional practice module into an OER which could be used to support both formal and independent learning.

Students as co-creators: All students enrolled on the professional practice module were invited to join the project team. The team $(n=7)$ met for a 'working lunch' for about ninety minutes each week. The students set the agenda for the meetings; typically, they discussed the classroom activities and prioritised those that were to be transferred into the online resource, shared practice, evaluated the learning objects produced and reflected on progress.

Students as experts: Current students on the professional practice module $(n=15)$ and students enrolled on the EDGE activity $(n=15)$ are using and evaluating the resource as well as identifying additional new features and tasks that could be added to the OER. The cycle of development and evaluation is depicted in Figure 1. The partnership model facilitated informal feedback from all three cohorts via discussion, observation of practice, and through various online fora. 


\section{Case Studies}

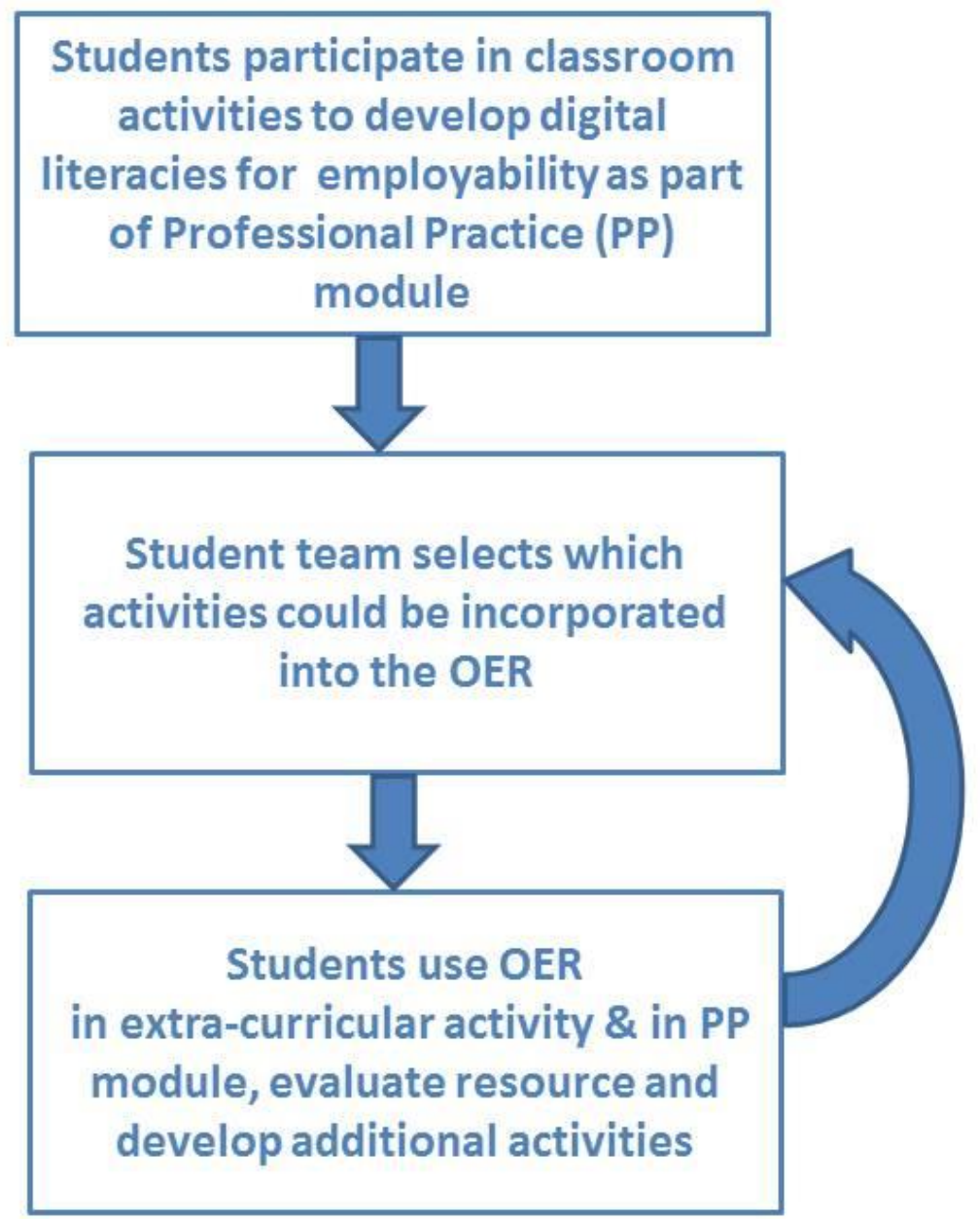

Figure 1: Development, evaluation and enhancement of an OER through active participation of students during accredited and extra-curricular activities.

\section{Software platform}

The project funder (HEA) stipulated that Xerte software should be used for each of the nine projects supported under the call (Digital Literacies in the Disciplines, 2014), in order to provide a consistent technical framework and to facilitate sharing of issues and good practice between the project teams. Xerte is freeware developed by the University of Nottingham for the production of interactive eLearning materials. It is a simple, wizard-based tool which can be used to compile content quickly and flexibly, create interactive activities and embed multiple types of media. There is also a growing repository of learning objects which are available for sharing, re-using, and re-purposing. The resulting learning objects can be accessed online and on most mobile devices. Xerte was installed on a local server within the Faculty and each of the participating students was provided with an individual account which she/he could use to develop content and experiment with the different tools available within the Xerte platform.

\section{Activities to develop digital literacies}




\section{Case Studies}

Several classroom-based and independent learning activities were used to support students in evaluating and developing their digital literacies as part of the professional practice module. The students decided which of these activities they wanted to incorporate into the OER. Table 1 provides an overview of the activities and the intended learning objectives, whilst the subsequent sections explore their use in practice and their incorporation into the OER.

\begin{tabular}{|l|l|}
\hline Classroom activity & Learning objective \\
\hline Visitor and Resident mapping & $\begin{array}{l}\text { Promote self-evaluation on the use of digital resources, socially } \\
\text { and for learning }\end{array}$ \\
\hline Self-evaluation using CASCADE quiz & Self-evaluation of digital skills and learning preferences. \\
\hline $\begin{array}{l}\text { Digital identity / developing a } \\
\text { professional profile }\end{array}$ & $\begin{array}{l}\text { Evaluation of digital identity (“Google Me”) } \\
\text { community }\end{array}$ \\
\hline Analysis of job advertisements & $\begin{array}{l}\text { Develop an understanding of what employers want and how to } \\
\text { evidence and articulate relevant experience }\end{array}$ \\
\hline Analysis of career options & Evaluating skills required for different careers / career paths \\
\hline 'Elevator pitch' videos & Articulating and evidencing relevant experience and knowledge. \\
\hline
\end{tabular}

Table 1: Classroom / independent learning activities in the Professional Practice Module

\section{Visitors and Residents}

In the first week, the Visitors and Residents (V\&R) mapping model facilitated discussions with students about their use of digital resources, both socially and for learning. The digital 'resident' has an online persona who may be observed in a social networking sites, blogs or image-sharing services, whilst the 'visitor' is an individual who takes a more pragmatic and focused approach to online resources (adapted from White and Le Cornu, 2011). After an introduction to the V\&R paradigm, students worked individually to identify and examine each of their digital resources and consider where and when they adopted a 'visitor' or a 'resident' approach. The students then plotted each of these tools on a two-dimensional grid, with a visitor-resident continuum along the $x$-axis and a social-learning continuum along the $y$-axis (Figure 2). Following sharing and discussion in small groups, these maps were refined and then fed back to the whole group, prompting a wider discussion on the use of technology and digital profiles. 


\section{Case Studies}

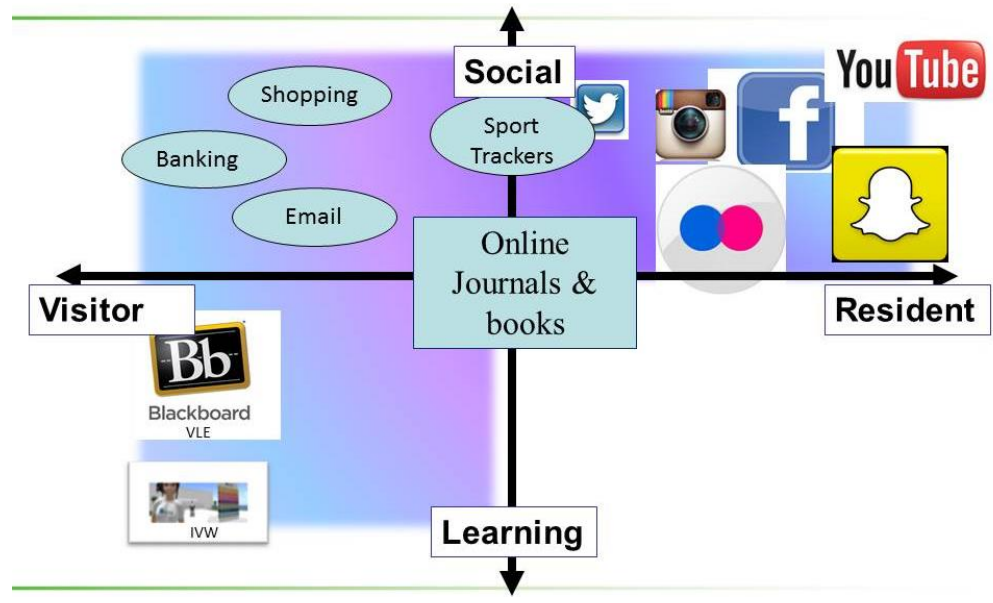

Figure 2: A composite produced from the general features of student maps. Analysis shows that students display resident behaviour when engaging socially and visitor behaviour when engaging with educational resources.

The V\&R model was an effective mechanism to engage with cohorts, particularly at the start of the academic year. It encouraged discussion on how and why particular tools and technologies were used, and prompted reflection on digital profiles and the steps that could be taken to promote a more positive digital identity. Results from the mapping exercises were broadly in agreement with other studies (for example Wright et al, 2013), indicating that, whilst students considered that they were competent users of technology in a social context, they are not optimising their use of technology in either their learning or in promoting their professional identity. Whilst the students agreed that the exercise provided a useful exploration of their online presence, they excluded this exercise from the OER following a consideration of the affordances that the face-to-face interaction provided.

\section{Self-evaluation activity using CASCADE quiz}

Students were asked to complete the online quiz "What type of digital learner am I?" (Exeter CASCADE Project, 2012), prior to attending the second class. The quiz comprises forty questions about use of technology, each of which students rate as either 'Not true of me", "Somewhat true of me" or "Very true of me". Figure 3 provides an illustrative example of the types of question in the quiz.

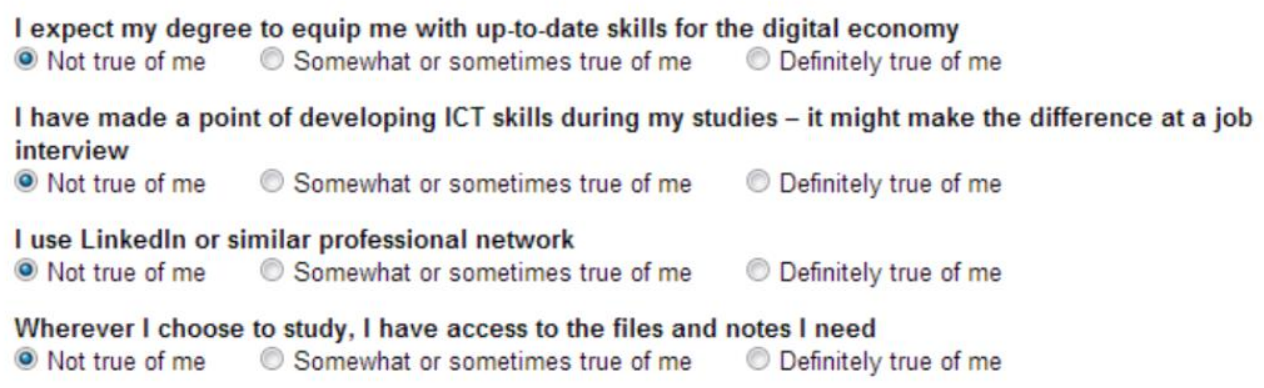

Figure 3: Illustrative examples of questions within the quiz. 


\section{Case Studies}

On completing the quiz, students are provided with an individual rating and learner profile identifying areas of digital scholarship where they have already demonstrated their competence, and areas which they could explore further to become more effective learners or improve their employability. Importantly, the feedback provides concrete tips for improving particular areas of digital scholarship. Students indicated that the tool provided an accurate evaluation of their skills and felt that the advice in the feedback was helpful in identifying the areas where they could improve their learning or employability, providing a valuable basis for developing a digital development strategy. The link to the quiz was added directly to the OER.

\section{Analysis of job advertisements}

This activity was based on an analysis of over 500,000 job advertisements (Benedictus, 2013) which revealed that the top ten most commonly-used words were:

- Commitment

- Organised

- Track record

- Communication Skills
- Motivation

- Qualified

- Flexible
- Passion

- Degree

- Innovative

Students worked in groups to consider what these words meant and discuss how they could provide evidence to demonstrate the requisite aptitude or experience. The students agreed that this activity could be effectively deployed using the interactive tools available in Xerte. They developed a 'drag and drop' tool which asked users to match evidence to job requirements.

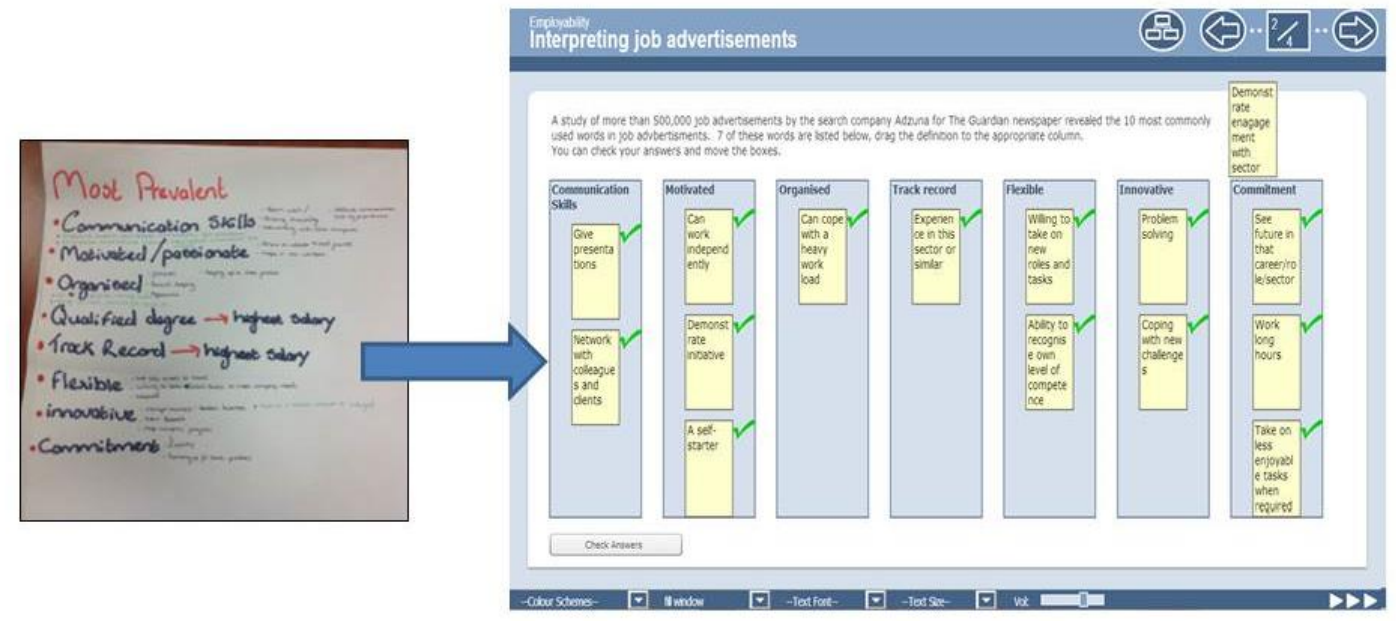

Figure 4: Students worked in groups to discuss the words used in job advertisements and then devised an interactive tool in Xerte which encouraged other users to consider how they would evidence and articulate how they met job requirements.

\section{Developing a digital identity for employability}




\section{Case Studies}

Working in pairs, students entered their partner's name into a search engine and evaluated the results, according to the following questions:

- Is there evidence of antisocial behaviour?

- Is there evidence of unprofessional behaviour?

- Is there evidence of engagement with subject area?

Whilst the so-called 'Google Me' activity did not reveal evidence of negative behaviour, there was also limited evidence of positive engagement with their subject area. Students were provided with suggested activities to develop a professional digital identity and a personal/professional learning network. The producers added guidelines to this activity into the OER and followed it with links to other public resources which they had found useful or informative.

\section{Career choices}

The students discussed the wide range of career choices available to them. Using resources such as the National Careers Service and relevant job advertisements, they examined job profiles to identify the desirable skills and determine how they might be evidenced. Links to resources were provided in the OER and a 'drag and drop' interactive tool was developed to help students think about how their digital profile provided evidence of these skills.
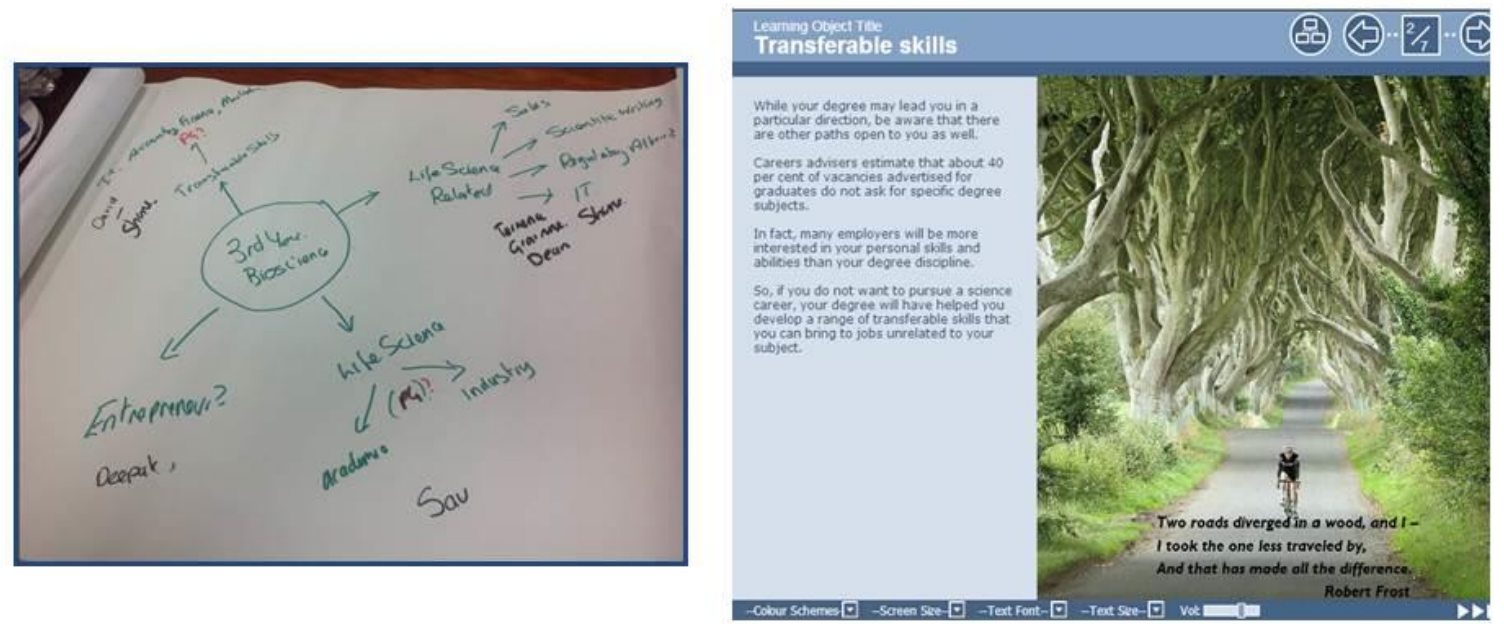

Figure 5: In the classroom activity, students explored the possible career options that were available to bioscience graduates. This was added to the OER by providing links to resources, information and an interactive tool.

\section{Elevator pitch}

Students were provided with a job specification for a start-up biotechnology company and asked to prepare a two-minute response to the question 'Why do you want this job?' The pitches were recorded in front of a mock interview panel and the videos shared with the individual student. They were asked to reflect on their performance and identify positive features in terms of content, presentation and areas for improvement. Following feedback from the panel, they were then invited to re-record their pitch. 


\section{Case Studies}

\section{Evaluation and lessons learnt}

Seven students originally started working on the project as co-producers of the digital content. They provided a range of reasons for wishing to be involved and illustrative comments include the following:

"I would like to be involved in the project because I don't have enough skills in employability, and I feel I can definitely develop it through Digital literacy project. Moreover as I am overseas student, this is all completely new for me, I would certainly learn something from such a challenging activity."

"I'd like to be involved in the project because I think it will help to develop my communication skills and it would be good to add to my CV. I've also worked in IT, have undertaken a few group projects before and together with my knowledge of Biotechnology I feel I could be of some benefit."

Over $50 \%$ of the students dropped out of the project as it progressed, citing other work pressures. Those remaining were committed to the development and dissemination of the resource and two students made presentations both internally and externally (Kilduff, et al. 2014). Including the development of the OER directly into the module may have encouraged more widespread or sustained engagement; however, offering it as an extra-curricular project engendered authentic partnership. Furthermore, giving students the opportunity to select which activities to embed into the resource gave them control over the project, in addition to providing an insight into the activities that students found most engaging or useful.

Though no-one in the student team had used Xerte before the start of this project, technical support was available in the Faculty to install Xerte on a local sever. It might have been valuable to have introduced some publicly-available Xerte objects to the class before getting students to develop their own resources; however, after a short learning curve, the team found Xerte intuitive and simple to use. The provision of individual accounts allowed students to develop content and experiment with the different tools within the Xerte platform. Though this flexible approach allowed individuals to develop areas of personal interest, it did mean that compiling the elements together into a cohesive resource was a challenge. Students attempted to embed most of the classroom activities into Xerte. This proved to be quite ambitious and it meant that some of the activities lacked a constructive narrative to describe to users how and why they should use a particular tool. Secondly, as a range of media can be easily incorporated into the learning objects, issues of copyright had to be regularly reinforced with students.

There was a wide difference in the digital literacies of the students, although they came from broadly similar academic backgrounds. The project was challenging: students were building a resource designed to support others in developing their digital literacies, which required development of their own skills in this area. These skills included information literacy and digital scholarship, which were effectively deployed in this authentic learning task. The students who went on to publicise and disseminate the resource further developed media literacy and communication skills. 


\section{Case Studies}

The $\underline{\mathrm{OER}}$ is now publicly available and is being evaluated and further developed by the current cohort of students on the professional practice module and through the EDGE activity. Engagement with the activity as producers or experts demonstrated that students appreciate the importance of developing their digital skills and competencies for their employability and to be efficient lifelong and life-wide learners.

\section{Reference list}

Benedictus, L (2013) 'Top 10 things employers are looking for.' The Guardian, 22 April 2013.

Available at: http://www.theguardian.com/money/2013/apr/22/top-10-thingsemployers-looking-for (Accessed: 09 September, 2013).

Bennett, S Maton,K and Kervin,L (2008) 'The 'digital natives' debate: A critical review of the evidence.' British Journal of Educational Technology, 39, 5, 775-786.

Digital Literacies in the Disciplines (2014) Available at:

http://dlind.referata.com/wiki/Main Page (Accessed: 10 October 2014).

EDGE Award (2012) Available at: http://edge.ulster.ac.uk (Accessed: 6 January 2014).

EDGE Award (2013): Category 4 Formal University-Wide Opportunities http://edge.ulster.ac.uk/documents/Category412sept13_001.pdf (Accessed: 6 January 2014)

Exeter CASCADE Project: Developing Digital Skills for Scholars (2013) Available at: http://projects.exeter.ac.uk/cascade/ (Accessed: 29 October 2013).

Hew, K. F., \& Cheung, W. S. (2013) 'Use of Web 2.0 technologies in K-12 and higher education: The search for evidence-based practice.' Educational Research Review, 9, 4764.

Kilduff, S., Skerret-Byrne, D. and Hack, C.J. (2014) 'An Open Education Resource to develop Digital Literacy Skills for Employability in the Life and Health Sciences through a staff-student partnership.' Available at: https://www.heacademy.ac.uk/resources (Accessed: 8 January 2015).

Tambouris, E., Panopoulou, E., Tarabanis, K. A., Ryberg, T., Buus, L., Peristeras, V. and Porwol, L. (2012) 'Enabling Problem Based Learning through Web 2.0 Technologies: PBL 2.0.' Educational Technology \& Society, 15,(4), 238-251.

Vivian, R., Barnes, A., Geer, R. and Wood, D. (2014) 'The academic journey of university students on Facebook: an analysis of informal academic-related activity over a semester.' Research in Learning Technology, 22.

White, D.S, and Le Cornu, A.(2011) 'Visitors and Residents: A New Typology For Online Engagement.' First Monday, [S.L.], August 2011. ISSN 13960466. Available at: http://Firstmonday.Org/Ojs/Index.Php/Fm/Article/View/3171/3049 (Accessed: 29 October 2013). 


\section{Case Studies}

Wright, F., White, D., Hirst, T. and Cann, A. (2014) 'Visitors and Residents: mapping student attitudes to academic use of social networks.' Learning, Media and Technology, 39(1), 126141.

Xerte Project Available at: http://www.nottingham.ac.uk/xerte/toolkits.aspx (Accessed: 31 March 2014). 